\title{
México en el Cono SUR: ASIlo diplomático \\ Y LECCIONES DE SU PRÁCTICA EN LOS AÑOS SETENTA
}

\author{
Mexico in the Southern Cone: Diplomatic ASYlum \\ AND LESSONS FROM ITS PRACTICE IN THE 1970s
}

\author{
Silvia Dutrénit Bielous ${ }^{\star}$ \\ DOI: https://doi.org/10.31644/ED.V7.N2.2020.A01
}

Resumen: Para la tradicional política de asilo mexicana, los años setenta resultaron significativos por confrontación con otras realidades. Resultaron, a la vez, significativos por los retos que la diplomacia debió sortear con el instrumento vigente (Convención de Asilo Diplomático de 1954). También lo fueron por las distintas apreciaciones sobre el riesgo de los solicitantes de protección, así como por los intereses particulares del Estado mexicano respecto a sus pares del sur latinoamericano.

Un acercamiento a las experiencias de Argentina, Chile y Uruguay hace posible observar consideraciones y variables que se le presentan a un mismo Estado asilante, el mexicano, ante realidades políticas en apariencia similares y simultáneas, pero que no lo eran en los hechos.

A partir de historiar sus aspectos distintivos, en el artículo se observan algunos asuntos medulares de la norma regulada en 1954. Asimismo, con esa observación será posible delimitar formas de interpretación y de su aplicación. Este recorrido desembocará en una posible explicación de las tensiones

\footnotetext{
* Profesora Investigadora Instituto de Investigaciones Dr. José María Luis Mora, México. Doctora en Estudios Latinoamericanos por la Universidad Nacional Autónoma de México, México. Maestra en Ciencias Sociales por la Facultad Latinoamericana de Ciencias Sociales, México. Licenciada en Historia por la Universidad Nacional Autónoma de México, México. Miembro del Sistema Nacional de Investigadores, Nivel III. Línea de investigación: Historia reciente de América Latina. Correo-e: sdutrenit@institutomora.edu.mx.

Fecha de recepción: 08/01/2020. Fecha de aceptación: 01/04/2020. Fecha de publicación: $31 / 07 / 2020$
}

(c) BY-NC-ND Páginas 6 - 32 
que se produjeron entre la norma y los hechos del asilo, advirtiendo que la primera no se ajustaba a las circunstancias en que se aplicó. La reflexión final es factible que sea útil a la luz de un nuevo y diverso presente, en donde se ubican protagonistas en la toma de decisiones, tanto en la (re) elaboración de los instrumentos jurídicos interamericanos como en los nacionales. Pero estas experiencias no deberían obviarse en la formación del cuerpo diplomático de las distintas cancillerías.

Palabras clave: asilo diplomático, embajadas, dictaduras, Cono Sur, México.

Abstract: For the traditional Mexican asylum policy, the 1970s proved significant by confrontation with other realities. They were also significant because of the challenges that diplomacy had to overcome with the existing instrument (Convention on Diplomatic Asylum of 1954). They were also significant because of the various perceptions of risk of the protection applicants, as well as for the particular interests of the Mexican State regarding its peers in Southern Latin America.

An approach to the experiences of Argentina, Chile and Uruguay makes it possible to observe considerations and variables presented to the same asylum State, Mexico, from political realities that appeared similar and simultaneous but that were not so according to the facts.

From writing the history of its distinctive aspects, the article observes some core issues of the norm regulated in 1954. From this observation, it will be possible to determine ways of interpretation and its application. This journey will lead to a possible explanation of the tensions between the norm and the facts of the asylum, highlighting that the former did not fit the circumstances in which it was applied. The final reflection is potentially useful in the light of a new and diverse present, where protagonists in the decision making are located, both in the (re)elaboration of the inter-American legal instruments as in the national ones. But these experiences should not be ignored in the formation of the diplomatic corps of the various chancelleries.

Keywords: diplomatic asylum, embassies, dictatorships, Southern Cone, Mexico. 


\section{Introducción}

El nuevo presente, a más de cuarenta años del otorgamiento de asilo diplomático por parte del Estado mexicano en los países del Cono Sur, evidencia matices y hasta diferencias respecto de aquellas circunstancias. Los años setenta del siglo XX marcaron un hito en su aplicación. Eran ańos en los que quedó establecida claramente, en especial por el Sistema Interamericano de Derechos Humanos, por las diferentes Comisiones de la Verdad y por tribunales nacionales e internacionales, la responsabilidad estatal en las violaciones de los derechos humanos. Ese contexto represivo resultó peligroso para la integridad y la vida de las personas ${ }^{1}$. Solo en algunas coyunturas, sin duda críticas como sucedió en Argentina en los años previos al golpe de Estado, podría quizá desdibujarse la responsabilidad estatal ${ }^{2}$. En los años ochenta no cesó esa represión, cometiéndose crímenes de lesa humanidad. En la actualidad se combinan con mayor énfasis en América Latina (A.L.) otros actores cuyos orígenes no necesariamente son políticos, complicidades y colusiones con estructuras estatales sin dejar de persistir la responsabilidad directa del Estado. Un mundo cambiante y complejo que conlleva a la vez tendencias de asilo no siempre en una misma dirección.

Referente a estas tendencias de asilo, el presente deja ver en las fronteras mexicanas a cientos de personas que esperan la concreción de sus solicitudes de asilo humanitario. Ello en virtud de las condiciones extremas de vulnerabilidad que sufren ante la violencia del crimen organizado. En su mayoría, proceden de Centroamérica, muchas se sitúan en la demarcación fronteriza mexicanaestadunidense, dado que es en el país del norte donde lo han solicitado. A las personas provenientes de Centroamérica se les suman las de otros países y, en particular, en la mencionada disparidad unas líneas más arriba, la de miles de mexicanos que lo reclaman.

Al menos 11 mil mexicanos esperan a lo largo de la frontera con Estados Unidos — desde Tijuana hasta Matamoros_ con la esperanza de recibir asilo humanitario en ese país, de acuerdo con la Universidad de Texas. Lo anterior

\footnotetext{
${ }^{1}$ En el Instituto Mora se desarrolló un proyecto de investigación sobre "Dictaduras y asilo: Experiencias en las embajadas mexicanas del Cono Sur”, del que fueron responsables Silvia Dutrénit Bielous y Guadalupe Rodríguez de Ita. En la argumentación de este artículo se retoman resultados de esa investigación de larga data, así como de textos de mi autoría y de coautoría publicados y referidos en la bibliografía. Se toman a la vez entrevistas del archivo generado en el proyecto entre la década del 90 y la del 2000 (ADACSIM).

${ }^{2}$ Situación que se hizo evidente en lo inmediato y hoy se encuentra documentada.
} 
coloca a México como puntero de los países de origen que más solicitudes de asilo humanitario piden a Estados Unidos desde su frontera sur, con 52 por ciento del total de personas en lista de espera. De acuerdo con un estudio del Centro Strauss para la Seguridad Internacional y Derecho, al que Milenio tuvo acceso, con cifras actualizadas en noviembre de 2019, un total de 21 mil 398 personas esperan por la respuesta a su solicitud de asilo humanitario en EU en al menos 11 ciudades fronterizas mexicanas (Ahmed y Villegas, 2019).

Estos datos, tomados de Milenio (Corral, 2019) por el New York Times (Ahmed y Villegas, 2019), hacen patente la crisis producida esencialmente por el accionar del crimen organizado en esta región de A.L. La situación producida tanto por la lentitud de los trámites como por el rechazo mayoritario a las solicitudes, en un contexto en el que México acordó medidas para frenar en su frontera sur la migración hacia Estados Unidos ${ }^{3}$, hace prever una reversión en el sentido de demandas de asilo de esos migrantes al Estado mexicano.

En la misma coyuntura en que, se intuye, esa corriente de solicitudes surgió, mientras se concluía la redacción de este artículo, tuvo lugar un suceso de asilo claramente político, el que México otorgó al mandatario boliviano Evo Morales. Para entonces, en noviembre de 2019, habiendo pasado poco tiempo de las elecciones que le permitían a este último comenzar un cuarto periodo de gobierno, se produjo una crisis institucional. La misma ha ocasionado un debate que no concluye respecto a si se trata o no de un golpe de Estado. En todo caso, lo que es relevante para el argumento de este artículo es que el gobierno mexicano lo interpretó como tal y actuó en consecuencia. Dicha interpretación dio lugar al ofrecimiento de asilo a Evo Morales, y a su correspondiente otorgamiento, como también a personalidades de su gobierno. Al respecto, el canciller mexicano Marcelo Ebrard

\footnotetext{
3 "México se comprometió con Estados Unidos a desplegar la Guardia Nacional con prioridad en la frontera sur para frenar la migración irregular, así como a recibir de vuelta a todos los solicitantes de asilo que crucen la frontera estadounidense, a cambio de la suspensión indefinida de los aranceles anunciados por Donald Trump contra productos mexicanos. En una declaración conjunta entre los gobiernos de ambos países y difundida por el Departamento de Estado de Estados Unidos, se informa que 'México dará pasos sin precedentes para incrementar la seguridad con el fin de detener la migración irregular'. También se indica que 'Estados Unidos expandirá inmediatamente la implementación de los ya existentes Protocolos de Protección a Migrantes, por lo que todos los solicitantes de asilo que crucen la frontera sur de aquel país serán rápidamente regresados a México, donde deberán esperar la resolución de sus demandas de asilo"” (Redacción AN, 2019).
} 
señaló que la operación militar en Bolivia -que llevó a la renuncia del mandatario Evo Morales- es similar a la orquestada en la década de los 70 en varios países latinoamericanos y se tradujeron en una serie de golpes de Estado. En Bolivia hay una operación militar en curso, la rechazamos, es similar a aquellos trágicos hechos que ensangrentaron nuestra América Latina el siglo pasado. México mantendrá su posición de respeto a la democracia y las instituciones (Olivares Alonso, 2019).

Al igual que en los años setenta, cuando se produjo el golpe de Estado en Chile, el gobierno mexicano decidió expresarse de forma proactiva respecto al otorgamiento de asilo, ofreciéndolo. Para el gobierno existía una situación de urgencia en virtud que la integridad y la vida del mandatario boliviano corrían peligro. Por ello, solicitó a las nuevas autoridades bolivianas que

...bajo el derecho internacional, proceda a otorgar el correspondiente salvoconducto y las seguridades, así como garantías de que la vida, integridad personal y libertad del señor Morales no serán puestas en peligro y que podrá ponerse en seguridad [y sostuvo que] el otorgamiento de asilo es un derecho soberano del Estado mexicano que va acorde con sus principios normativos en política exterior para proteger los derechos humanos y respetar la autodeterminación de los pueblos, la solución pacífica de las controversias y la no intervención (Lafuente, 2019).

Incluso, al igual que en aquel momento en Chile, cuando se trasladó a la familia del presidente Salvador Allende ${ }^{4}$ y a un primer grupo de asilados que se encontraban en la embajada mexicana en Santiago, se envió un avión para que Evo Morales pudiera abandonar Bolivia.

Es así que, después de mucho tiempo que el asilo por causas políticas no ocupaba la atención pública en México, en este presente adquiere notoriedad y se suma no solo a la sostenida demanda de solicitudes de connacionales al gobierno estadunidense, sino también a las de otras nacionalidades que lo hacen al gobierno mexicano.

\footnotetext{
${ }^{4}$ Véase el desarrollo de los acontecimientos de esos asilos en las capitales de Chile, Argentina y Uruguay, en los textos de Buriano (ed.), Dutrénit y Rodríguez (2000), Dutrénit, Hernández y Rodríguez (2002) y Dutrénit (2002). Así también puede consultarse para el caso chileno el trabajo de Rojas (2020) y para el argentino el de Yankelevich (2010).
} 
No obstante las similitudes que en el caso del mandatario boliviano se han manifestado respecto a lo ocurrido en los años setenta, un acercamiento oportuno a aquellas circunstancias permitirá observar un contexto político y doctrinario particular. Asimismo, con el acercamiento, se constata la inexistencia de una violencia generalizada provocada por el crimen organizado y en su lugar una práctica sistemática del terrorismo de Estado.

Las páginas que siguen ofrecen una síntesis analítica sobre las experiencias de asilo diplomático de México en el Cono Sur. Esta síntesis permite observar lo acontecido y aprehenderlo como conocimiento, aunque también comprenderlo y así extraer algunas lecciones para el presente. El hilo argumental contiene en forma implícita algunas preguntas rectoras, como son: ¿cuáles fueron las singularidades y cuáles las diferencias en la aplicación del asilo? y ¿qué experiencias quedan como enseñanza para nuevas modificaciones al contenido de las convenciones de asilo?

Con la sistematización se fija la atención en los años en que, dominadas por la Doctrina de Seguridad Nacional (DSN), se instalaron dictaduras en los países del Cono Sur y México otorgaba, con diferencias significativas, asilo diplomático en sus embajadas. Lo realizado reconoce su origen en un proyecto de investigación de las décadas de los noventa y el 2000, que se llevó a cabo con una estrategia metodológica cualitativa, de laboriosa investigación de campo y archivística, que atendió y confrontó especialmente documentos oficiales -diplomáticos y migratorios- con fuentes orales. Los testimonios obtenidos corresponden a integrantes del personal diplomático y a asilados de los distintos países. La realización de las entrevistas focalizadas contó con cuestionarios semi estructurados ${ }^{5}$.

El artículo está organizado en cuatro apartados que van conduciendo el entendimiento del problema que se busca desarrollar, hasta desembocar en las conclusiones. Una extensa bibliografía referida se presenta en las páginas finales.

\section{Aquellos años en pocas imágenes}

Durante la segunda mitad del siglo XX, en A.L. se vivieron décadas en las que se atentaba contra la libertad y la vida de las personas en un área muy extendida del sur latinoamericano. Se vivían situaciones de ruptura del orden

\footnotetext{
${ }^{5}$ Véase nota 1.
} 
institucional y militarización estatal inspiradas en la Doctrina de Seguridad Nacional (DSN), en donde se procuraba eliminar al "enemigo interno" y refundar un nuevo orden estatal ${ }^{6}$. Las dictaduras que fueron cubriendo la geografía esencialmente conosureña, emparentadas con esa concepción doctrinaria, diseñaron una estrategia represiva que se extendió ignorando las fronteras nacionales, en una coordinación que se conoce como Operación Cóndor y que cumplió la función de aplicar el terrorismo de Estado, no sólo entre los tres países que se abordan en este análisis, sino también, con Brasil, Paraguay y Bolivia?.

Si bien nada de lo sucedido fue ajeno a la temporalidad de la guerra fría, presentando similitudes en las modalidades y ritmos, cada experiencia nacional estuvo estrechamente ligada a sus tradiciones históricas y políticas. En un arco que cubrió el ciclo golpista y dictatorial, cada país resultó singular en sus coyunturas y procesos. En todo caso, coincidieron en que la represión fue muy vasta, en la medida también que la concepción del enemigo interno alcanzaba a amplias capas de la población. Los perseguidos por los regímenes dictatoriales constituían una masa humana voluminosa, estaban incluidos los

${ }^{6}$ Hizo posible un basamento ideológico en el sentido de que el enfrentamiento bipolar Este - Oeste tenía una expresión nacional y que, en ella, existía el enemigo interno que quería destrozar los Estados. Véase Leal Buitrago (2003).

${ }^{7}$ Es interesante detenerse en dos documentos de diplomáticos estadunidenses que evidencian el trabajo coordinado de la inteligencia militar, así como el grado de involucramiento de su país. Uno corresponde al cable del 28 de septiembre de 1976, del coronel Scherrer, agregado de asuntos legales de la embajada en Argentina, en el que se registra la creación de esta coordinación entre las fuerzas armadas de la región. Su expedición se dio un mes después del atentado contra Orlando Letelier, funcionario del gobierno de la Unidad Popular. Pese a estar censurado en varias partes, da una definición de los objetivos del Cóndor, de los países miembros e incluso sugiere que el atentado contra Letelier fue responsabilidad de esta coordinación. "FBI, Operation Condor" cable (1976). El segundo cable, del 20 de octubre de 1978, fue remitido a Cyrus Vance, secretario de Estado, por el embajador en Paraguay, Robert White. El mismo refiere a una conversación con Alejandro Fretes Dávalos, jefe de las Fuerzas Armadas paraguayas. Allí se anota que los jefes de inteligencia sudamericanos implicados en el Cóndor 'mantienen contacto entre sí a través de una instalación de comunicaciones estadounidense, colocada en la zona del Canal de Panamá, que cubre a toda América Latina' y que dicha instalación 'es utilizada para coordinar información de inteligencia entre los países del Cono Sur'. Sobre el final del telegrama, el embajador White expresa su preocupación ante la posibilidad de que la conexión de Estados Unidos al Cóndor fuese revelada en las investigaciones en torno al asesinato de Orlando Letelier: 'Sería aconsejable', sugiere White, 'revisar este arreglo para asegurar que su continuación conviene a los intereses de Estados Unidos”. (State Department cable. US. Ambassador Robert White (Paraguay) to Secretary of State Cyrus Vance, 1978). Véase sobre la Operación Cóndor el libro de Calloni (1999). 
militantes y dirigentes políticos y gremiales, sus familiares y amistades, incluso intelectuales, artistas, profesionales y un número importante de personas que, por su trabajo, sus ideas o sus obras eran considerados enemigos "subversivos".

En ese ambiente represivo, que dio lugar a una cotidianidad de terror, los caminos que aquellos perseguidos tomaron fueron diversos y las condiciones individuales desembocaron en situaciones variadas. Detención, tortura, prisión permanente, secuestro, desaparición, ejecución, clandestinidad, cotidianidad silenciada, sin duda miles y decenas de miles fueron los que necesitaron resguardarse. Un volumen significativo en cada país tomó el camino del exilio, lo que provocó la llegada de miles de conosureños a los diferentes continentes. Pero ese camino tuvo distintas rutas porque al exilio se llega por diversos atajos. Entre ellos el de la protección diplomática, el asilo en las embajadas. Fue la senda, comparativamente, que menos se transitó, asimismo se debe decir que no todos los que la procuraron, la lograron. Quienes así la tomaron, con o sin éxito, recurrieron a un derecho contemplado en las convenciones interamericanas, al instrumento jurídico denominado asilo diplomático (Buriano y Dutrénit, 2003).

\section{El asilo diplomático en su institucionalidad jurídica}

La figura del asilo se trata de una de las instituciones de derecho internacional con orígenes más añejos. De manera remota, se ubica como la protección de quienes delinquían y buscaban protegerse de la autoridad civil y terrenal, optando por acogerse a la protección religiosa (Francioni, 1973).

Las características con que se conoce actualmente aparecen al iniciar el siglo XX: en sentido estricto se aplicó para perseguidos por delitos políticos ${ }^{8}$ como un derecho omnímodo y soberano del país otorgante del asilo, que está exento de la obligación de justificar las razones por las que tomó la decisión. La redefinición de este instrumento para la protección de quienes entran en controversia con su Estado y son perseguidos por razones políticas tuvo variantes que condujeron a una mayor delimitación en su regulación. En aquel inicio del siglo, más cercano a su fundación, los Estados mostraron no sólo incapacidad para defender a sus nacionales, sino se fueron convirtiendo

\footnotetext{
${ }^{8}$ No obstante, el primer ordenamiento en materia de asilo para los perseguidos políticos se registró en 1823. México y Colombia fueron los suscriptores de ese tratado de no Extradición por Delitos Políticos. Apoyado en Senado de la República Mexicana (1974: 630).
} 
en perseguidores y violadores de los derechos fundamentales de la nación, atentando contra los derechos del hombre (Agamben, 1996: 46).

La permanente inestabilidad política de la región en la centuria pasada provocó el incremento de la apelación al instrumento de asilo. Esta situación promovió su revisión en distintas Convenciones Interamericanas, realizadas en Montevideo (1928), La Habana (1933) y Caracas (1954), hasta convertirse en una institución tradicional de derecho convencional latinoamericano (Díaz y Rodríguez de Ita, 1999).

En 1954 se llevó a cabo, en Caracas, la X Conferencia Interamericana; entre sus actividades se firmó la Convención de Asilo Diplomático. En esta conferencia se asentaron avances significativos en la delimitación del instrumento jurídico. Los aportes se ubican en la precisión de los términos más que en la introducción de aspectos novedosos (Unión Panamericana, 1961). Básicamente, las especificaciones establecidas fueron las siguientes: la precisión de que el asilo sólo procederá para perseguidos por motivos (delitos) políticos, la determinación de los lugares donde podría otorgarse y la clarificación de los derechos y las obligaciones de los Estados, tanto asilante como territorial.

En la misma X Conferencia Interamericana se reguló el asilo territorial. Desde ese momento se reconocen dos tipos de asilo: territorial y diplomático, los cuales se distinguen de la siguiente forma. El territorial se otorga a quienes son perseguidos políticos en su Estado de origen y logran ingresar dentro de las fronteras geográficas del Estado asilante. El diplomático resulta el más controversial porque pone en tensión la soberanía de los Estados y se apoya en la defensa de los derechos esenciales de los hombres cuando el Estado territorial no ejerce la función de respecto o garantía. De esta forma, el asilo diplomático es el que se concede dentro del territorio del Estado que ejerce la persecución, y se ampara en la noción de la inmunidad diplomática de las representaciones. Por tanto, reivindica el centenario principio de inviolabilidad de las sedes diplomáticas.

Fue esta última revisión del instrumento de asilo diplomático la que se aplicó con aciertos y controversias cuando, en Argentina, Chile y Uruguay, se ejerció una represión extrema y cotidiana contra los opositores. 


\section{Experiencias de México en la aplicación de asilo diplomático}

Pese a las precisiones alcanzadas, la regulación del asilo diplomático que emergió de la Convención de Caracas de 1954 resultó insuficiente para su aplicación en los años setenta y ochenta. Vale la pena tener presente lo que evocó en una entrevista Gonzalo Martínez Corbalá, quien fuera embajador mexicano en Chile en el momento del golpe de Estado. "[El instrumento de asilo diplomático era de] apenas 16 o 17 cuartillas, digamos no da para mucho, es un arma corta, difícil de manejarse para defender las vidas de los que solicitan el asilo" (Martínez Corbalá, 1997).

Con un articulado laxo, el documento no especifica, por ejemplo, los tiempos en los que el Estado territorial está obligado a expedir salvoconductos (Artículos XI y XII). A la vez, deja en la indefinición lo que se entiende por lo establecido en el Artículo XX, al referir que: "El asilo diplomático no estará sujeto a reciprocidad. Toda persona, sea cual fuere su nacionalidad, puede estar bajo la protección del asilo" (Unión Panamericana, 1961). En este aspecto, no precisa si un extranjero puede recibir asilo diplomático en otro Estado donde es perseguido, aunque no sea el propio9. Según testimonios recogidos en la investigación aludida anteriormente, con percepciones diplomáticas in situ, esta imprecisión dio lugar a desestimar solicitudes de protección en medio de la acción represiva desatada por la Operación Cóndor en los tres países y otros más. Sin duda, desde el presente, con una abultada -aunque no total-y documentada información proveniente de archivos de inteligencia nacionales y en especial, del Departamento de Estado de los Estados Unidos (U.S. Department of State, 2020) ${ }^{10}$, es factible afirmar que esa vaguedad en la definición tuvo serias repercusiones que afectaron el espíritu protector con que fue concebida la Convención de Asilo Diplomático de 1954 (Buriano (ed.), Dutrénit y Rodríguez, 2000; Dutrénit, Hernández y Rodríguez, 2002; y Dutrénit, 2002).

En todo caso, se debe recordar que, si bien existía el precedente del nazifascismo, primer gran movimiento contemporáneo cuya concepción biopolítica quebró la asociación entre el hombre y el ciudadano (Agamben, 1996: 45-46) y persiguió a los oponentes y excluidos fuera de las fronteras,

\footnotetext{
${ }^{9}$ Entre otras omisiones, o no precisiones, se encuentran la del asilado, que debe ser trasladado a un tercer Estado y la no devolución al país perseguidor en caso de que no se mantenga la autorización de residencia en el país asilante. Véase en Imaz (1993: 60).

${ }^{10}$ Consúltese la información en su portal: https://foia.state.gov/
} 
ese escenario no fue visualizado como posible para América Latina a mediados del siglo XX. Además, el fenómeno dictatorial de los setenta y ochenta ${ }^{11}$ fue diferente en su diseńo a lo que aconteció durante la primera mitad del siglo XX en Europa. En el Cono Sur los que se dieron no fueron procesos de dominación militar de un Estado sobre otro, sino una coordinación de las fuerzas armadas de varios países para la eliminación de un enemigo común. La misma se concretó en Santiago de Chile sobre finales de 1975, sin embargo, comenzó a visualizarse en Argentina en $1974^{12}$.

También es posible intuir que muchas circunstancias de represión sobre los perseguidos se hubieran evitado, en especial en Argentina, si una mayor precisión respecto al otorgamiento de asilo diplomático fuera del país de nacimiento del solicitante estuviera especificada en la Convención de 1954. Sin duda, también, la percepción y disposición del diplomático in situ hubiera subsanado la opacidad de la norma.

Si estos sucesos se piensan y ponderan a partir de la experiencia de México como Estado asilante, no es posible obviar que el otorgamiento de protección diplomática no resultaba algo novedoso. Desde el siglo XIX se conoce su condición de país asilante y, en especial, la afirmó y desarrolló durante el siglo $\mathrm{XX}$, tanto desde un punto de vista filosófico como práctico. Innumerables episodios individuales y grupales dan cuenta de la acogida que México dio a distintas corrientes ideológicas a lo largo de su historia ${ }^{13}$. Esta conjunción filosófica y práctica se plasmó durante décadas en una recepción que, a su vez, estuvo basada en el acuerdo tácito de no actuación en política interna. Se trató de una protección acompañada de los ajustes en la legislación, de una política exterior regida por el principio de "no intervención" y de una tensión entre política interior y exterior ${ }^{14}$.

\footnotetext{
${ }^{11}$ Esta afirmación no ignora que el primer golpe de Estado que dará paso a una dictadura de ese tipo fue en Brasil en abril de 1964.

${ }^{12}$ Se recomienda hacer una lectura de Butazzoni (2014).

${ }^{13}$ Algunas de las diversas experiencias de asilo que otorgó México se pueden apreciar en las siguientes líneas. En un breve recorrido destacan grupos liberales y de la izquierda política latinoamericana y europea. Por ejemplo, llegaron a México latinoamericanos como José Martí, Jacobo Arbenz, Héctor Cámpora, la familia Allende, y miles de centroamericanos, caribeños, sudamericanos, europeos como León Trotsky y otros muchos miles de republicanos espańoles. Apoyado en Segovia (1995), Imaz (1995), Serrano Migallón (1998 y 2000).

${ }^{14}$ Un acercamiento a esta tensión se puede leer en Dutrénit Bielous (2015) y una visión crítica sobre la política de asilo desde la experiencia chilena se localiza en Rojas (2016).
} 
La opción preferencial por México no estuvo basada, generalmente, en el conocimiento del país que tuvieran los solicitantes de asilo, sino en el hecho de que lo consideraran la "alternativa posible" (Buriano, Dutrénit y Rodríguez, 2000: 63). El Estado mexicano fue predominantemente un "promotor pasivo", que aplicó una tendencia a recibir "sin impulsar" las solicitudes con un celoso apego a la regulación interamericana.

Sin embargo, la historia da cuenta de dos excepciones en la historia del asilo: la española y la chilena, únicos casos en los que México fue su "promotor activo”. Según Serrano Migallón (2001), en ambos posiblemente intervino el interés del ejecutivo, del presidente en especial, por cambiar la imagen internacional, además de la ya tradicional política de otorgar protección.

Cuando aconteció el voluminoso refugio a los republicanos, probablemente lo que se dio fue el interés del presidente Lázaro Cárdenas (1934-1940) por demostrar una posición internacional clara, nítida, en favor de los derechos humanos. Respecto al asilo proactivo en el caso de Chile, la consideración al respecto se encuentra en distintas entrevistas realizadas a propósito de la experiencia de asilo mexicano en su embajada en Santiago, en el marco del proyecto de investigación referenciado. Las fuentes orales dan también la idea del marcado peso de la intervención presidencial para dar protección a los perseguidos mediante el asilo diplomático. La amistad personal que sostenía el presidente Luis Echeverría Álvarez (1970-1976) con el presidente Salvador Allende es también reiteradamente reconocida ${ }^{15}$. Mientras que el embajador mexicano en Argentina en 1976, Roque González Salazar (1998), en una entrevista sugirió la preocupación del presidente Echeverría por el prestigio internacional de México y lo vinculó con un posible interés en exhibir una imagen distinta luego de los sucesos del 68.

Lo que se aprecia en los casos estudiados es que el otorgamiento de asilo cuenta con esa impronta resumida en el interés del ejecutivo que deviene en instrucciones diplomáticas, pero que no obvia un fuerte y reiterado componente discrecional. Es decir, su éxito práctico ha estado vinculado

\footnotetext{
${ }^{15}$ La actuación del presidente Echeverría fue diferente en los países del Cono Sur. En especial, un comportamiento se tuvo ante el golpe en Chile y otro frente al de Argentina. Y seguramente ello fue así por diversas razones, entre ellas, la amistad personal con el presidente Allende, su proyección y fuerza simbólica, así como la simpatía que despertaba la forma como Allende había llegado a la presidencia. Respecto al presidente Echeverría no se descarta, por cierto, el interés por posicionarse mejor como líder del Tercer Mundo.
} 
históricamente a la decisión del embajador in situ. No obstante lo afirmado, es necesario sumar y valorar la intervención de otras variables: las estrategias de los Estados territoriales y del Estado asilante, así como las de quienes buscan resguardarse de la persecución. Si observamos los acontecimientos de los años setenta, se distinguen gobiernos dictatoriales con distintas estrategias respecto a México, y viceversa, como diversas fueron también las decisiones de los perseguidos respecto a solicitar o no la protección diplomática. Sobre lo ocurrido respecto al asilo diplomático en los ańos setenta del siglo pasado, en particular, se encuentra una información aproximada sobre el volumen de las personas que llegaron a México. Se trata de alrededor de 1300, como cifra total de las tres embajadas. Dicha información proviene de los documentos resguardados en el Archivo Histórico Diplomático de la Secretaría de Relaciones Exteriores. Este número, aún aproximado, representa a quienes solicitaron protección diplomática y fueron beneficiados con la calificación de asilados en las embajadas de Buenos Aires, Santiago de Chile y Montevideo. Es necesario anotar que la información existente en el repositorio diplomático presenta variaciones en las cifras debido a que en los registros se contabilizan acompañantes y familiares, así como mexicanos que se encontraban en situación de riesgo en aquellos países.

Esta información recabada fue confrontada, cuestionada y enriquecida con fuentes orales, lo que hace posible, por ejemplo, preguntarse ¿por qué una diferencia tan marcada del número de asilados entre los países del área frente a situaciones en apariencia similares? Teniendo en cuenta que son cifras aproximadas, en Chile fueron 800 los asilados, en Uruguay 400 y en Argentina apenas 60 , con 30.000 muertos y desaparecidos en el curso de la represión ${ }^{16}$. Las historias políticas nacionales tuvieron sus particularidades y sólo lo ocurrido en cada caso hace posible arriesgar algunos intentos explicativos.

El otorgamiento de asilo mexicano en el Cono Sur comenzó en Chile con el golpe de Estado del 11 de septiembre de 1973. Otras muchas embajadas procedieron de la misma forma. En Santiago, la embajada de México recibió en pocas horas a decenas de solicitantes de asilo. Ello fue acompañado de la decidida actitud del embajador Martínez Corbalá (1998), que no sólo dio protección de inmediato, sino que arriesgó su vida yendo a buscar a quienes

\footnotetext{
${ }^{16}$ Los 30.000 es una cifra referida por los organismos de derechos humanos, y la de 11000 corresponde a una revisión del informe de la Comisión Nacional sobre la Desaparición de Personas (CONADEP).
} 
corrían peligro y conduciéndolos en su coche a la sede diplomática. Como ejemplo, se puede señalar el caso más notorio, el de la familia Allende Bussi. Isabel Allende lo rememora con nitidez,

Cuando me comuniqué a la embajada fue muy sorprendente porque yo marqué y salió Gonzalo. Era evidente que estaba en espera. Estaba alerta, esa es la palabra. Y le dije: 'Gonzalo...' y él me dijo '¿Dónde estás?', o sea, yo prácticamente no tuve que identificarme, Gonzalo me reconoció, creo que alcancé a decirle: 'Soy Isabel', pero nada más, por teléfono ‘¿Dónde estás?'... Poco rato después de haber llamado a la embajada mexicana aparece un auto de proporciones, digamos, un auto bastante grande que en realidad poco se usaba en los setenta, un auto imponente, venía Gonzalo Martínez Corbalá acompañado de una persona conocida con apellido Del Valle...Y Gonzalo traía un papel en la mano, que era un salvoconducto, porque estamos hablando del día 11, o sea, que está prohibido circular para todos los ciudadanos. El día 12 , y entonces, el miércoles 12 , y él traía un salvoconducto y el salvoconducto decía, exacto: 'Autorización, Embajador de México, etcétera, para circular, retirar, retirar -decía- Isabel Allende Bussi e hijos menores' (Allende, 1997).

Esa forma de gestionar la protección puso en situación de peligro al embajador. En pocos días, y luego del primer viaje que trasladó asilados, efectuado el 15 de septiembre, el presidente Echeverría giró instrucciones para que se retirara de su misión diplomática en virtud del peligro que corría en Chile. Pese a su retiro, México mantuvo sus puertas abiertas a los solicitantes, aun cuando las condiciones se fueron modificando. Los asilados poco a poco viajaron a México, hasta que quedó un grupo algo menor a la centena, al que el Estado territorial negaba los salvoconductos. Finalmente, con el otorgamiento de la documentación, la salida para México se dio en junio de 1974. Fecha que marcó el cumplimiento directo de la política de asilo y el comienzo de repliegue hasta la ruptura de relaciones diplomáticas ${ }^{17}$. Al igual que con la España franquista, las relaciones se retomaron una vez que concluyeron los regímenes dictatoriales.

En cambio, en Argentina, el clima de fuerte y sangrienta confrontación, con las listas de sentenciados a muerte por la Triple A, obligó a muchos de los

${ }^{17}$ Véanse en AHDREM sobre Chile el exp- III-6018-1 (5a. Parte), sobre Argentina el exp. III5921-10 (1 $1^{\text {a }}$ Parte) y sobre Uruguay el exp- III-5923-5 ( $1^{\text {a }}$ y $2^{\text {a }}$ partes). 
perseguidos políticos a buscar rutas de emigración antes del golpe de Estado del 24 de marzo de 1976. Sin una ruptura institucional y carente de una acción visible de responsabilidad estatal, el asilo como tal no era, según la norma, una ruta viable. La acción de los grupos paramilitares fue muy intensa durante el gobierno de Isabel Martínez de Perón, no solo eran los sentenciados quienes aparecían en las listas o se les anunciaba de alguna forma esa situación, también lo eran los ejecutados, con los distintos ritos de muerte plasmados en sus cuerpos ${ }^{18}$.

Fue así que, alrededor de un año y medio antes del golpe de Estado, Argentina transitaba esta crisis que ponía en duda el equilibrio del orden institucional. No obstante, aunque según la norma no estaban dadas las condiciones para el asilo, a la embajada mexicana acudían quienes lo solicitaban. En esos momentos, según lo evocado por el embajador mexicano González Salazar (1998), se optó mayoritariamente por aceptar a quienes, efectivamente, estaban en situación de riesgo de su libertad o de su vida, protegiéndolos con la figura de "huéspedes o invitados".

Sin embargo, cuando se consumó el golpe de Estado, fue muy evidente una más restringida disposición para acoger asilados en la embajada mexicana. Esto se manifestó en trámites más apegados a la regulación con un rigor mayor en la formalidad. La situación la rememoran algunos asilados como Guillermo Greco: "Fui a la embajada, me atendieron amablemente y me dijeron que volviera el mes que viene...” (Greco, 1997). De manera similar lo evoca Gonzalo Vaca Narvaja: "Claro, se armó un despelote bárbaro en la embajada, el que estaba ahí no era el embajador, no sé si era alguno de los asesores de la cancillería, nos dijo que no, nos dijeron que fuéramos por los canales normales" (Vaca Narvaja, 1997).

Había una evidente distancia entre el espíritu de la norma y su aplicación. En testimonios de solicitantes de asilo se rememoran estas circunstancias que, de alguna manera, se contradicen con las circunstancias previas, en parte, durante la permanencia del mismo embajador ${ }^{19}$.

\footnotetext{
${ }^{18}$ Véase sobre el accionar de los grupos paramilitares, y la Triple A en particular, el texto de Eidelman (2018).

${ }^{19}$ En el libro Tras la memoria... de Buriano Castro, Dutrénit Bielous y Rodríguez de Ita (2000) y en el documental De dolor y esperanza... de Dutrénit Bielous, Hernández y Rodríguez de Ita (2002) se recogen la totalidad de entrevistas realizadas durante los ańos del proyecto (ver nota 1) que hacen posible sostener y argumentar esta perspectiva de las distintas experiencias del asilo mexicano en los países del Cono Sur.
} 
No puede desconocerse que esta actitud multiplicó el riesgo para los solicitantes y desanimó a muchos que optarían por no intentarlo. Para quienes pudieron eludir la persecución, la opción fue la búsqueda de otros caminos. A partir de entonces, un sistemático relevo de diplomáticos acompañó el trabajo de una embajada que se caracterizó por tener en su residencia tres asilados durante años, el que más permaneció lo hizo durante casi todo el periodo que perduró la dictadura (1976-1982). A diferencia de lo ocurrido en Chile, y algo similar a lo acontecido en Uruguay, en Argentina fueron pocas las embajadas que dieron protección.

El golpe de Estado en Uruguay del 27 de junio de 1973, ejecutado por el presidente constitucional, Juan María Bordaberry, fue antecedido de un creciente autoritarismo que ubica su comienzo en torno a 1968. La escala represiva se dirigió contra gremialistas y sindicalistas y en contra de la guerrilla urbana y sus sectores de apoyo. El resultado fue el asesinato, la detención y tortura, la prisión y el camino del exilio. Muchos perseguidos abandonaron el Uruguay antes de consumado el golpe de Estado. Sin embargo, la estrategia de represión masiva contra sectores políticos, sindicales y gremiales se extremó hacia el año de 1975, año y medio después de consumado el golpe, lo que determinó una tardía afluencia de asilados a la embajada de México. Fue en esa embajada en donde existieron mejores condiciones de obtener asilo con un riesgo relativamente menor de perder la vida en el intento de alcanzarlo ${ }^{20}$. Fue en esa representación diplomática donde existió una enérgica decisión del embajador Vicente Muñiz Arroyo de defender la vida de los perseguidos. Su actitud era de primero proteger y luego confirmar si el solicitante realmente requería del asilo. Un caso extremo de defender a quién requería protección, y valentía también, ocurrió en el consulado mexicano cuando Federico Falkner llegó y desesperadamente gritó "asilo político" mientras era apresado a golpes por personal de inteligencia policial que esperaba su posible aparición.

\footnotetext{
${ }^{20} \mathrm{El}$ peligro de perder la vida, o al menos la libertad, fue una realidad en las embajadas en Montevideo. Ejemplos de esa extrema situación sucedieron con la maestra María Elena Quinteros, secuestrada por fuerzas de inteligencia policial de los jardines de la embajada de Venezuela e inmediatamente desaparecida, y en el caso de Federico Falkner, cuyo secuestro de los corredores del consulado mexicano fue impedido, como se aprecia en el fragmento testimonial que se incluye en estas páginas, por la decidida actuación del primer secretario de la embajada mexicana, Gustavo Maza Padilla.
} 
Pero resulta que como no conocía el lugar, además, fui a dar por una escalera que terminaba en una especie de mezzanine, en un primer piso... al final opté por el elevador. Y bueno, ya bajando en el pasillo del elevador a pesar de que yo iba medio tapado, con una bufanda, más que camuflado llevaba una bufanda... Uno [del personal de inteligencia] me venía a agarrar los testículos, otro por ejemplo, sacó inmediatamente el arma que me tenía encañonado ... Entonces, yo gritaba como desesperado 'asilo político' ¿no? y estos me trataban de bajar y yo... siempre digo que tuve una suerte y además de suerte, bueno, agradezco enormemente, la actitud que tuvieron, bueno en este caso este funcionario de la embajada Gustavo Maza, y el conjunto de funcionarios de la embajada. Porque, en medio del escándalo sale este hombre, en ese momento Gustavo era, Gustavo Maza era el primer secretario tengo entendido de la embajada en ese momento... y con voz enérgica y dice: '¿Qué es lo que está pasando acá, qué es lo que pasa?, esto es territorio mexicano'. Me soltaron inmediatamente (Falkner, 1997).

La actitud de Maza, personal y no ajena a las instrucciones que giró a todo el personal diplomático, tuvo en Martínez Corbalá su par en cuanto a sensibilidad y solidaridad con los perseguidos y, sin duda, la reconocida valentía en esas condiciones de peligro por la enconada represiva (Dutrénit Bielous, 2011). El fuerte viraje en la política de asilo se produjo en 1977 cuando, meses después de iniciado el nuevo sexenio gubernamental (diciembre de 1976) con la presidencia de José López Portillo, se reemplazó al embajador Muñiz Arroyo por quien puso trabas al trámite de asilo, el militar Rafael Cervantes Acuña. El nuevo embajador extremó al mínimo el otorgamiento de asilo y sostuvo en un informe que,

la facilidad de obtener asilo en la Embajada de México, comentario generalizado en Montevideo, se vio frenada a la llegada del suscrito por el intenso esfuerzo de calificar correctamente los casos que se presentaron en gran número, con la obvia intención de aprobar cuál sería la tónica del nuevo embajador... (Cervantes Acuña, 1977). 
Cervantes Acuña, además, condicionó la aceptación a que el asilado se comprometiera a no residir en México y que este país fuera utilizado exclusivamente como área de tránsito hacia otro destino.

Ahora bien, como ha sido posible apreciar, la mecánica golpista tuvo desfases en el tiempo. Primero aconteció en Uruguay, luego en Chile y finalmente en Argentina. Esta diferencia temporal de los golpes de Estado y las características de los periodos previos estimularon a que muchos perseguidos procuraran, como primera opción, cruzar las fronteras y resguardarse en los países vecinos según las coyunturas que se iban dando. Es este aspecto, es necesario relacionar el desplazamiento con la Operación Cóndor y la regulación y aplicación del asilo diplomático.

La experiencia concreta de lo ocurrido en los países de la región indica que, en Argentina, por ejemplo, no se aceptaron solicitudes de extranjeros. Hay que recordar que el golpe argentino fue cronológicamente más tardío y que el proceso político transitó entre la breve "primavera", como se le llamó al gobierno de Héctor Cámpora, y el posterior accionar de la Triple A, hasta finalmente el golpe de Estado. Esta situación desembocó en un tránsito y residencia en su territorio de muchos perseguidos políticos de los países fronterizos, particularmente uruguayos y chilenos, aunque también, brasileños, paraguayos y bolivianos. Por tanto, muchos "no nacionales" o extranjeros requirieron de protección diplomática en la sede diplomática mexicana en Buenos Aires sin que pudieran obtenerla. Lo contrario ocurrió en Chile, donde fue efectivo el refugio diplomático, así como también en Uruguay. Con el triunfo de la Unidad Popular en 1970, se había producido una concentración de perseguidos de otros países y de colaboradores del entonces campo socialista, y sus solicitudes fueron atendidas y resueltas ${ }^{21}$.

Dado que el operar coordinado de los servicios de inteligencia (Operación Cóndor) significó una extensión de la persecución en toda la geografía de los Estados involucrados y aún más ${ }^{22}$, se debe entender lo siguiente: el asilo

\footnotetext{
${ }^{21}$ Apoyado en AHDREM, caso chileno en exp. III-6018-1 (5a. Parte).

${ }^{22} \mathrm{Al}$ respecto, es altamente ilustrativa la documentación del Departamento de Estado, E.U.A., de la CIA y de otros organismos de seguridad de este país, desclasificada a partir de 1999. Esta abunda en datos relativos a acciones realizadas en el marco de esta operación para el exterminio de opositores. Particularmente esclarecedores son los documentos que refieren a los asesinatos de los diputados uruguayos Zelmar Michelini y Héctor Gutiérrez Ruiz, y del ex presidente de Bolivia, Juan José Torres, ocurridos en Argentina. Véase: Case Number: 200000044, No. Doc. 1976BUENOS03462; 1976BUENOS03460; el memorando 7611578
} 
diplomático era requerido por quienes temían la pérdida de la libertad o de la vida sin que ello significara que su nacionalidad correspondía a la del territorio en donde se encontraban. Recuerda Maluza Stein que “...ninguna embajada, digamos, me aceptaba porque yo estaba en condición de apátrida, digamos, porque en Uruguay yo ya no tenía asilo, no tenía documentos brasileños, no tenía documentos uruguayos, y en fin, a no ser la embajada mexicana..." (Stein, 1996). Llamamos la atención en este punto porque la regulación es muy clara en cuanto a que el asilo diplomático debe otorgarse al perseguido político dentro de su propio país, pero muy imprecisa para quienes lo requieren fuera de su Estado natal. De manera evidente, esta regulación resultó anacrónica en los años en que acontecían las dictaduras del Cono Sur y requiere que se atienda en el presente, un mundo globalizado, que tiende tímidamente a extender e integrar la defensa de los derechos humanos, pero propende aún más a universalizar la violación de los mismos (Dutrénit Bielous, 2004).

Pese a los aciertos y los deslices, entre el sentido de la norma y su aplicación, en que fue otorgado o rechazado el asilo diplomático en las experiencias aludidas, hay que entender que los tiempos y circunstancias en que le fue demandado a México no fueron muy distintos a las solicitudes en otras sedes diplomáticas. Lo que vale la pena subrayar es que México destacó, en algunos de los países en los que fue requerido, por su disposición a otorgarlo, aunque con diferentes características y condicionantes en la calificación (Dutrénit Bielous, 2002).

Concedida la protección y otorgado formalmente el asilo, la suerte fue diversa en lo que respecta a la permanencia de las personas dentro de las embajadas antes de abandonar el país. Ello dependió de la discrecionalidad con la que se manejaron los Estados territoriales en el tiempo y forma de entrega de la documentación (salvoconducto) que garantizara una salida sin

y otra vastísima documentación relativa a estas acciones conjuntas contenidas en los Nacional Security Archive (http://www.gwu.edu/ nsarchiv). Abunda, también, la información relativa a la captura de refugiados chilenos en Argentina, en "Chilean refugees in Argentina", (State Argentina Declassification Project Collenction, 1975; 1976) y 12 de mayo 1976, State Argentina Declassification Project Collection, en http://www.foia.state.gov/documents/ Argentina/00009F3D.pdf y en la misma colección, 14 de mayo 1976, en http://www.foia. state.gov/documents/Argentina/00009F3F.pdf, así como la detención y muerte de ciudadanos argentinos en Uruguay, “Tortured to death in Uruguay -22 known cases, Amnesty International report, october 31, 1975, State Argentina Declassification Project Collection en http://www. foia.state.gov/documents/Argentina/00009FBF.pdf 
riesgos para los asilados. Esa discrecionalidad provoca otra tensión que no logra resolverse con la regulación de 1954 y que hoy está presente en el caso de la embajada en Bolivia. En Santiago de Chile, la temporalidad mayor de permanencia de los asilados en la residencia diplomática fue de cerca de 9 meses. Como se mencionó, se trataba del grupo de los altos funcionarios y políticos gubernamentales. En Uruguay no excedió el año, aunque fue particularmente conflictiva la expedición de documentación para los militares asilados (activos o retirados) que se encontraban en las instalaciones del consulado en Montevideo.

Mientras el caso extremo aconteció en la embajada mexicana en Buenos Aires, donde la permanencia se dio por algunos años. De ahí que no es exagerado decir que la dictadura argentina trató de convertir a esa embajada en una especie de cárcel para las tres figuras destacadas del peronismo ${ }^{23}$. La referencia es al ex-presidente Cámpora, quien la habitó tres largos años y pudo viajar a México cuando médicos militares corroboraron que padecía un cáncer terminal. Cuando ocurre su fallecimiento, meses más tarde, le otorgan el salvoconducto a su hijo; mientras que Abal Medina, ex-secretario general del Partido Justicialista, vivió dentro de la embajada mexicana algo más de seis años.

Para Abal Medina en aquellos años

Llegamos a estar absolutamente solos [Héctor Cámpora, Héctor Cámpora (hijo) y yo], absolutamente solos... Toda la primera época [más de un año y medio] estuvimos, estuvimos absolutamente aislados. Yo veía a mis hijos, pasaban por la tarde, eran muy chiquitos, frente a la embajada... Yo los veía desde la ventana... retirados nos veíamos [después de ese año y medio empecé a verlos] pero... esporádicamente, no era un asunto fácil... Inicialmente bueno, inicialmente nada más teníamos la prensa, las normas del asilo diplomático establecen que '... los asilados no deben tener contacto con [el exterior]'... Entonces todo primer argumento se cumplió minuciosamente, llegado un determinado momento, en que, bueno, el cumplimiento de la Argentina era tan grotesco y con el visto bueno de las, de los embajadores con alguna excepción... procedí a realizarme como [en mi casa] (Abal Medina, 1997). ${ }^{23}$ Caracterización que toma José Reveles (1980) para titular su libro: Una cárcel mexicana en
Buenos Aires. 
Esta permanencia superó lo que la historia latinoamericana y la ficción literaria tenían registrado, pero no así en la experiencia internacional, que lo supera ${ }^{24}$.

El asilado argentino que estuvo más tiempo se convirtió en algo así como en el "anfitrión" que despedía y recibía nuevos embajadores (Buriano (ed.), Dutrénit y Rodríguez, 2000; WHA, 1981; y Bernetti, 1981), hecho que confirma, una vez más, que lo real maravilloso de la novelística latinoamericana es, en ocasiones, más tímido que la propia realidad de estos países ${ }^{25}$.

\section{Para concluir}

Regresando al comienzo de este artículo, y mientras se escriben las últimas líneas, se conoce el asedio que se está viviendo en la embajada de México en La Paz, Bolivia. Ante ello, y en medio de una creciente tensión diplomática producida por la negación de Bolivia, como Estado territorial, de otorgar los salvoconductos a los asilados que se encuentran en la embajada mexicana, agudizada por el conflicto con diplomáticos españoles, México declara que denunciará la situación ante la Corte Internacional de Justicia (CIJ) de La Haya $^{26}$. Es así que, si bien el artículo está acotado a un fenómeno migratorio del siglo pasado, el asilo conosureño en las embajadas mexicanas de los años setenta-ochenta, su interés resulta de actualidad. El asilo diplomático en general, dentro del gran fenómeno de las migraciones forzadas relacionadas con el exilio y el refugio, ha sido considerado como "una casuística", una especie de género menor por su escasa significación cuantitativa. No obstante, desde el

\footnotetext{
${ }^{24}$ Apenas tres ejemplos, uno lejano, el del cardenal Mindszenty que permaneció 15 años en la embajada de Estados Unidos en Hungría; otro, fue el caso de Haya de la Torre en la embajada de Colombia en Perú; y uno más cercano, el de Julian Assange, fundador de WikiLeaks, quien estuvo más de 6 ańos en la representación diplomática ecuatoriana en Inglaterra.

${ }^{25}$ Nos referimos concretamente al texto de Carpentier (1972), El derecho de asilo, publicado años antes del episodio.

${ }^{26}$ El instrumento jurídico se presentó debido al asedio que la representación está sufriendo por la violación de obligaciones diplomáticas por parte del Estado boliviano. México acogió a personalidades del gobierno de Evo Morales desde noviembre. Algunos de ellos fueron posteriormente requeridos. Lo acontecido atenta contra la soberanía de México con órdenes retroactivas y ha manifestado que no entregará a los asilados. Desde el 15 de noviembre pasado se esperan los salvoconductos. Bolivia se manifestó como “...país respetuoso de la Convención de Viena sobre relaciones diplomáticas...” pero al mismo tiempo manifestó que la subsecretaría mexicana objeta de forma el pedido que hizo su gobierno de entrega de los asilados que tienen órdenes de aprehensión por la supuesta comisión de delitos comunes. Apoyado en Jiménez (2019).
} 
punto de vista del derecho interamericano y de las relaciones internacionales es relevante. Además, y no menos significativo, es un instrumento importante en cuanto a la protección de los derechos humanos.

En torno al asilo se configuraron un conjunto de circunstancias, se elaboraron una serie de instrumentos del derecho internacional y, en las últimas décadas, se fue generando un importante rescate documental que, aunado a la desclasificación de información oficial de varios Estados, obliga a pensar en la propuesta que hiciera Chesneaux (1981), siempre oportuna, de rememorar, de no "hacer tabla rasa" del pasado.

Una de las tareas que se imponen en este nuevo milenio es confrontar la regulación del asilo a la luz de la experiencia histórica, de la suerte corrida por la norma y su aplicación en el último tercio del siglo pasado, de sus aciertos y de sus límites o fracasos. Al respecto, la experiencia mexicana es insustituible para la revisión, el análisis y ofrecer lecciones.

Una observación y estudio de la documentación sobre las experiencias en esas embajadas, de Argentina, Chile y Uruguay, hace posible extraer algunas consideraciones que dejaron huella. Los avatares, los éxitos y los límites que sufrió la institución del asilo al confrontarse con la realidad estudiada exigen una proyección de futuro que, de alguna manera, se pretende incentivar con la mirada presentada en este artículo. Lo cierto es que la recurrencia de episodios en América Latina y en México parece indicar que sigue vigente, que el asilo es, desafortunadamente, un pasado presente. Y lo es aunque solo se acotara la práctica de asilo a la otorgada a Evo Morales y algunos funcionarios de su gobierno.

Se sabe que la realidad trasciende a estos casos. En ese sentido, en el pasado se encuentran experiencias que muestran actualidad y, sobre todo, ofrecen lecciones sobre posibilidades y trabas para hacer efectivo el derecho de asilo y otros derechos que no deberían ser violentados. Se está en un presente que abrumadoramente sitúa a los mexicanos ante la desesperación y desamparo de miles de personas migrantes. Al mismo tiempo, son los propios mexicanos quienes se enfrentan a la desesperante situación de solicitar asilo.

En síntesis, se puede afirmar que con estas páginas no se pretende agotar la riqueza de la experiencia mexicana, pero sí se busca resaltar que hay tres elementos básicos que se reiteran en los distintos sucesos narrados. Estos elementos pueden abonar en un mismo sentido o dominar uno sobre los otros, 
resultando no siempre a favor del cumplimiento del derecho de asilo. Esos elementos básicos para la experiencia de México son: la tradición histórica del asilo, el interés gubernamental de aplicarlo y la sensibilidad e interés de sus diplomáticos en cada una de las situaciones que se presentan.

Ahora bien, se debe reiterar que, aunque otros son los tiempos y otros los contextos, los derechos humanos deben protegerse y promoverse. Por tanto, es necesario, entre otros aspectos, considerar la imperiosa necesidad de una regulación acorde a los tiempos actuales que, a partir de las experiencias del pasado, sea capaz de atender los requerimientos del presente y el futuro.

\section{Bibliografía}

Agamben, Giorgio (1996) "Política del exilio", Archipiélago: cuadernos de critica de la cultura. No. 26-27, pp. 41-52.

Ahmed, Azam y Villegas, Paulina (2019) “'Esto se lleva toda la esperanza': una regulación impide el asilo en EE. UU. para la mayoría de los solicitantes". The New York Times en español, [online] Disponible en: https://www.nytimes.com/es/2019/09/13/espanol/america-latina/ mexico-asilo-suprema-corte-migrantes.html (consultado el 13 de septiembre de 2019).

Bernetti, Jorge Luis (1981) "Salvoconducto para Abal Medina", en Uno Más Uno. 13 de abril, México. (ADACSIM)

Buriano Castro, Ana (ed.), Silvia Dutrénit Bielous y Guadalupe Rodríguez de Ita (2000) Tras la memoria: el asilo diplomático en tiempos de la Operación Cóndor. México: Instituto de Investigaciones José María Luis Mora/Instituto de Cultura de la Ciudad de México.

Buriano Castro, Ana y Dutrénit Bielous, Silvia (2003) "En torno a la política mexicana de asilo en el Cono Sur", Historia Actual Online, 0(2), pp. 59-68. Disponible en: https://historia-actual.org/Publicaciones/ index.php/hao/article/view/20

Butazzoni, Fernando (2014) Las cenizas del Cóndor. Montevideo: Planeta. 
Calloni, Stella (1999) Los años del Lobo: Operación Cóndor. 2da. ed. Buenos Aires: Peña Lillo/Ediciones Continente (Biblioteca del Pensamiento Nacional).

Carpentier, Alejo (1972) El derecho de asilo. Barcelona: Lumen.

Cervantes Acuña, Rafael (1977) Informe de Labores, 1976-1977. México: Dirección General de Archivo, Biblioteca y Publicaciones/SER, pp. 26-27.

Chesneaux, Jean (1981) ¿Hacemos tabla rasa del pasado?: a propósito de la Historia y de los historiadores. México: Siglo Veintiuno.

Corral, Adyr (2019) "Esperan más de 21 mil en la frontera por refugio en EU; la mitad, mexicanos". Milenio, [online] Disponible en: https:// www.milenio.com/policia/esperan-21-mil-frontera-refugio-unidos (consultado el 12 de noviembre de 2019).

Díaz, Luis Miguel y Rodríguez de Ita, Guadalupe (1999) "Bases históricas jurídicas de la política mexicana de asilo diplomático" en Dutrénit Bielous, Silvia y Rodríguez de Ita, Guadalupe (eds.) Asilo diplomático mexicano en el Cono Sur. México: Instituto de Investigaciones Dr. José María Luis Mora/SER. pp. 63-83.

Dutrénit Bielous, Silvia (2015) "Encrucijadas del exilio uruguayo: una observación basada en los agostos mexicanos de 1977 y 1978", Projeto História. Revista do Programa de estudios pós-graduados de História, No. 53, Mai-Ago de 2015, pp. 57- 86.

Dutrénit Bielous, Silvia (2011) La Embajada Indoblegable. Asilo mexicano en Montevideo durante la dictadura. Montevideo: Editorial Fin de SigloICP/UdelaR.

Dutrénit Bielous, Silvia (2004) "Para repensar la Convención de Asilo Diplomático de 1954. (Lecciones de la práctica mexicana ante las peticiones en el Cono Sur)", Cuadernos Americanos. Nueva época, 105 (3), pp. 168-185.

Dutrénit Bielous, Silvia (2002) "Persecución política y derecho de asilo diplomático: alcances y límites del instrumento jurídico", Iberoamericana, No. 24 (2), pp.17-30.

Dutrénit Bielous, Silvia, Carlos Hernández y Guadalupe Rodríguez de Ita (2002) De dolor y esperanza. El asilo un pasado presente [documental] México DF: Instituto de Investigaciones Dr. José María Luis Mora/ Consejo Nacional de Ciencia y Tecnología. 
Eidelman, Ariel (2018) "La actividad paraestatal en la Argentina a principios de los años setenta” en D’Antonio, Débora (comp.) Violencia, espionaje y represión estatal. Seis estudios de caso sobre el pasado reciente argentino, Buenos Aires: Imago Mundi. pp. 27-58.

Francioni, Francesco (1973) Asilo diplomatico: Contributo allo studio delle consuetudini locali nel diritto internazionale. Milano: Giuffre.

Imaz, Cecilia (1993) "El asilo diplomático en la política exterior de México", Revista Mexicana de Política Exterior. Nueva época, 40-41. pp. 53-71.

Imaz, Cecilia (1995) La política del asilo y del refugio en México. México: Potrerillos Editores.

Jiménez, Néstor (2019) "Denuncia México a Bolivia ante Corte de la ONU”. La Jornada Maya, [online] Disponible en: https://www. lajornadamaya.mx/2019-12-27/Denuncia-Mexico-a-Bolivia-ante-

Corte-de-la-ONU (consultado el 27 de diciembre de 2019)

Lafuente, Javier (2019) "México otorga asilo político a Evo Morales". El Pais, [online] Disponible en: https://elpais.com/internacional/2019/11/11/ actualidad/1573504978_938761.html (consultado el 12 de noviembre de 2019).

Leal Buitrago, Francisco (2003) "La doctrina de Seguridad Nacional: materialización de la guerra fría en América del Sur", Revista de Estudios Sociales, No. 15, pp. 74-87. Disponible en: https:// es.scribd.com/ document/172829727/Leal-Buitrago-La-Doctrina-de-SeguridadNacional.

Martínez Corbalá, Gonzalo (1998) Instantes de decisión: Chile, 1972-1973. México: Grijalbo.

Olivares Alonso, Emir (2019) "México ofrece asilo a Evo Morales; la SRE exige respeto a su embajada en La Paz". La Jornada, [online]. Disponible en: https://www.jornada.com.mx/2019/11/11/politica/009n1pol (consultado el 11 de noviembre de 2019).

Redacción AN (2019) "México acordó frenar migración irregular con Guardia Nacional y recibir más”. Aristegui Noticias, [online] Disponible en: https://aristeguinoticias.com/0706/mexico/mexico-acordofrenarmigracion- irregular-con-guardia-nacional-y-recibir-masmigrantesdevueltos- por-estados-unidos/ (consultado el 7 de junio de 2019). 
Reveles, José (1980) Una cárcel mexicana en Buenos Aires. México: Proceso. Rojas Mira, Claudia Fedora (2016) "La Política de Asilo en México: una Perspectiva Crítica”, Revista Divergencia, No. 6 (5), pp. 69- 80. Disponible en: http://www.revistadivergencia.cl/wp-content/ uploads/2018/11/05.pdf.

Rojas Mira, Claudia Fedora (2020) Las moradas del exilio: la Casa de Chile en México, 1973-1993. México: Centro de Investigaciones sobre América Latina y el Caribe-Universidad Nacional Autónoma de México.

Senado de la República Mexicana (1974) Tratados ratificados y convenios ejecutivos celebrados por México y Colombia. México: Senado de la República Mexicana.

Segovia, Rafael (1995) "La difícil socialización del exilio", Nexos, Vol. 18 (205), pp. 65-69.

Serrano Migallón, Fernando (1998) El asilo político en México. México: Porrúa. Serrano Migallón, Fernando (2000) México, tradición de asilo y refugio. México: Secretaría de Gobernación, Comisión Mexicana de Ayuda a Refuguados.

State Argentina Declassification Project Collection (1975) Tortured to death in Uruguay, 22 known cases. Disponible en: http://www.foia.state.gov/ documents/Argentina/00009FBF.pdf.

State Argentina Declassification Project Collection, (1976) Chilean Refugees in Argentina. Disponible en: http://www.foia.state.gov/documents/ Argentina/00009F3D.pdf.

State Department cable. US. Ambassador Robert White (Paraguay) to Secretary of State Cyrus Vance (1978) Subject: Second meeting with Chief of staff re Letelier case. Disponible en: www.gwu.edu/ nsarchiv/ news/20010306/condor.pdf.

Unión Panamericana, (1961) Convención sobre Asilo Diplomático suscrita en la Décima Conferencia Interamericana, Caracas, 1-28 marzo de 1954. (Tratados 18). Washington: Secretaría General Organización de los Estados Americanos, Unión Panamericana.

WHA (1981) "World's Record Soon to be Established for Forced Stay in an Embassy" en WHA. 17 de junio de 1981.

Yankelevich, Pablo (2010) Ráfagas de un exilio. Argentinos en México, 19741983. Buenos Aires: Fondo de Cultura Económica-El Colegio de México. 


\section{Entrevistas}

Abal Medina, Juan Manuel (1997) Entrevista realizada a Juan Manuel Abal Medina [Entrevista realizada por Silvia Dutrénit Bielous y Guadalupe Rodríguez de Ita] 12 de marzo de 1997, Ciudad de México (ADACSIM).

Allende Bussi, Isabel (1997) Entrevista realizada a Isabel Allende Bussi [Entrevista realizada por Gabriel Gaspar], 27 de mayo de 1997 , Santiago de Chile (ADACSIM).

González Salazar, Roque (1998) Entrevista realizada a Roque González Salazar [Entrevista realizada por Silvia Dutrénit Bielous], 14 de mayo de 1998, México, D.F. (ADACSIM).

Greco, Guillermo (1997) Entrevista realizada a Guillermo Greco [Entrevista realizada por Lucía Cargnel], 25 de agosto de 1997, Buenos Aires (ADACSIM).

Martínez Corbalá, Gonzalo (1997) Entrevista realizada a Gonzalo Martínez Corbalá [Entrevista realizada por Silvia Dutrénit Bielous], 11 de diciembre de 1997, México, D.F. (ADACSIM).

Serrano Migallón, Fernando (2001) Entrevista realizada a Fernando Serrano Migallón [Entrevista realizada por Silvia Dutrénit Bielous], 5 de junio de 2001, México, D.F. (ADACSIM).

Stein, Maluza (1996) Entrevista realizada a Maluza Stein [Entrevista realizada por Gerardo Caetano], 18 de diciembre de 1996, Montevideo (ADACSIM).

Vaca Narvaja, Gonzalo (1997) Entrevista realizada a Gonzalo Vaca Narvaja [Entrevista realizada por César Tcach], 4 de junio de 1997, Córdoba (ADACSIM). 